\title{
Circulating and tissue catecholamines in rats with chronic neurogenic hypertension
}

\author{
P. Dominiak, F. Kees, and H. Grobecker \\ Lehrstuhl für Pharmakologie, Universität Regensburg, Regensburg (F.R.G.)
}

\begin{abstract}
Summary: To study the role of peripheral catecholamines in plasma and different tissues in neurogenic hypertension we measured directly blood pressure, maximum rate of left ventricular pressure rise $\left(\mathrm{dp} / \mathrm{dt}_{\max }\right)$ and heart rate through an aortic catheter 5 weeks after total sino-aortic baroreceptor deafferentation in male Sprague-Dawley rats. Blood samples were collected through the same catheter to determine plasma catecholamine concentrations. Blood pressure and $\mathrm{dp} / \mathrm{dt}_{\max }$ were significantly higher in neurogenic-hypertensive rats when compared with sham operated rats. Plasma noradrenaline concentrations and plasma adrenaline concentrations reached significantly higher levels in neurogenic-hypertensive rats. In the heart noradrenaline content was lower (when calculated per $g$ wet weight) and in the adrenal medulla adrenaline content was higher in neurogenic-hypertensive rats, when compared with sham operated controls. A significant positive correlation was found between $\mathrm{dp} /$ $\mathrm{dt}_{\max }$ and plasma noradrenaline concentrations.

It is concluded that sino-aortic baroreceptor deafferentation produces a significant chronic hypertension, probably supported by elevated plasma catecholamine concentrations and enhanced synthesis and release of adrenaline from adrenal medulla.
\end{abstract}

Key words: neurogenic hypertension, rats, haemodynamics, catecholamines, tissue, plasma

\section{Introduction}

Genetic and experimental animal models of hypertension presenting some characteristics to those found in human essential hypertension have been developed $(8,24)$. Central and peripheral sympathetic nerves have been recently demonstrated to play a role in these models $(16,17,29,30)$. The participation of sympathetic neurons in selected cases of human essential hypertension has been postulated as well (11). For this reason, an in-depth study of sympathetic activity in adequate animal models could be useful to advance our knowledge of the sympathetic factor(s) possibly involved in the human disease.

One of the well studied animal models of experimental hypertension is that of neurogenic hypertension (20). This model is produced by total surgical sino-aortic deafferentation in dogs (6), rabbits (9), and rats (20). In the rat, neurogenic hypertension develops immediately and persists chronically $(2,5,12,20)$. From the results obtained both the peripheral (2) and central $(5,27)$ sympathetic systems were proposed to be involved in the development of this model. Alexander et al. (2) reported a correlation between elevated blood pressure and increased dopamine- $\beta$-hydroxylase activity in plasma of rats with neurogenic hypertension. In addition to sympathetic nerves, evidence is rapidly accumulating on a role of the adrenal medulla in neurogenic as well as in other animal models of hypertension, and in selected cases of human essential hypertension $(11,16,17)$.

Plasma dopamine- $\beta$-hydroxylase however, at least in man, may not be a very good index of rapid changes in sympathetic nerve activity (26). The determination of changes in plasma 
levels of noradrenaline both in animals and man offers more useful information (15). In addition, the state of the art technology for determination of plasma catecholamines $(7,25)$ allows the simultaneous determination of adrenaline levels and gives an index of adrenomedullary activity in so far as production and release of catecholamines are concerned (19). The study of catecholamine metabolism in important target organs, such as the heart, could provide additional valuable information in hypertension studies. Heart catecholamines have been demonstrated to be involved in animal models of experimental hypertension (28).

For the reason outlined above we undertook the study of plasma, adrenal and heart catecholamine levels in conscious, unrestrained rats with chronic neurogenic hypertension and their sham-operated controls. We compared these levels with basic haemodynamic parameters (systolic and diastolic blood pressure, heart rate, $\mathrm{dp} / \mathrm{dt}_{\mathrm{max}}$ ). Our results suggest that peripheral sympathetic nerves and adrenal medulla are involved in the development of neurogenic hypertension in the rat.

\section{Methods}

\section{Animals}

Male Sprague-Dawley rats (SIV 50) from Dr. Ivanovas, Kisslegg, Germany, weighing about $250 \mathrm{~g}$ before baroreceptor deafferentation were used. Animals were housed individually in plastic cages (Makrolon $\left.{ }^{\circledR}\right)$ in an air-conditioned, light-dark-cycled $(12 \mathrm{~h})$ room with lights on from $6 \mathrm{a}, \mathrm{m}$. to $6 \mathrm{p} . \mathrm{m}$. They were given food (Altromin ${ }^{(3)}$ standard diet) and tap water ad libitum. Animals remained in our laboratory for one week prior to use.

\section{Surgical procedures}

Total sino-aortic deafferentation was performed as described by Krieger (20). Atropine $(1.4 \mathrm{mg} / \mathrm{kg}$ i.p.) was administered and the rats were subsequently anaesthetized with ether. Through a ventral neck incision the carotid artery and the vagus were carefully dissected from the sympathetic trunk bilaterally. A $1 \mathrm{~cm}$ long strip of the sympathetic trunk was resected on both sides. The carotid sinus was separated bilaterally from the connective tissue and was stripped of nerve fibers. The carotid sinus was then painted with $10 \%$ phenol (dissolved in $95 \%$ ethanol). In addition, the cervical sympathetic trunk and a section of superior laryngeal nerves were resected. A sham operation was performed by isolating the sympathetic trunk and the carotid sinus on both sides without resection.

\section{Physiological measurements}

Four and a half weeks after sino-aortic deafferentation, an indwelling catheter (PE-50, Clay Adams, Parsippany, N.J., USA) was placed into the thoracic aorta through the right carotid artery, and heparine (125 I.U.) injected twice daily. Three days after catheter implantation, blood pressure, maximum rate of left ventricular pressure rise $\left(\mathrm{dp} / \mathrm{dt}_{\max }\right.$, paper speed: $\left.100 \mathrm{~mm} / \mathrm{s}\right)$ and heart rate were recorded in conscious rats for five to ten minutes with a Statham pressure transducer (P $23 \mathrm{~dB})$, five minutes after connecting the pressure transducer twice daily $(8$ a.m., 5 p.m.) over a period of 6 days. Blood pressure of rats was measured throughout the experiments in a quiet room, without handling. During the entire blood pressure measurement procedures the rats had no sight contact with the person carrying out the experiments.

At the end of the 5th week, immediately after blood pressure measurement, blood samples $(0.3-0.5$ $\mathrm{ml}$ ) were taken from the catheters in conscious rats without handling for determination of the plasma catecholamine concentrations. Animals were then killed by decapitation under ether anaesthesia and the adrenal glands and hearts were removed and placed immediately in liquid nitrogen. Plasma and organs were kept frozen at $-70^{\circ} \mathrm{C}$ until they were assayed. 


\section{Determination of catecholamines}

Plasma catecholamines were assayed radioenzymatically by the method of Peuler and Johnson (25) with ion pair extraction according to the method of daPrada and Zürcher (7), using purified catechol-Omethyltransferase. Hearts were homogenized with a glass homogenizer ( $F$. Braun) in $5 \mathrm{ml} 0.1 \mathrm{n} \mathrm{HClO}_{4}$ containing $2.5 \%$ EDTA and $2.5 \% \mathrm{Na}_{2} \mathrm{~S}_{2} \mathrm{O}_{5}$. Each pair of adrenal glands was homogenized in $500 \mu \mathrm{l}$ $0.1 \mathrm{n} \mathrm{HClO}_{4}$ containing $2.5 \%$ EDTA and $2.5 \% \mathrm{Na}_{2} \mathrm{~S}_{2} \mathrm{O}_{5}$. After centrifugation the catecholamines in the supernatant were determined with high performance liquid chromatography (HPLC, F. Waters) and electrochemical detection (ELCD, F. Bioanalytical Systems Inc. USA, West Lafayette) using dihydroxybenzylamine as an internal standard (Kissinger et al. 1981).

\section{Statistical analysis}

Data were statistically evaluated using Student's unpaired t-test and standard linear regression analysis. The results are expressed as mean \pm SEM (31).

\section{Results}

Haemodynamic changes

The mean value of all blood pressure measurements in rats with neurogenic hypertension $(131 / 107 \pm 1.8 / 1.5 \mathrm{~mm} \mathrm{Hg}, \mathrm{n}=8)$ was significantly increased $(\mathrm{p}<0.001)$ over that of shamoperated normotensive control rats $(108 / 84 \pm 1.7 / 1.3 \mathrm{~mm} \mathrm{Hg}, \mathrm{n}=7)$ when measured directly over a period of 6 days in the morning and the afternoon during the 5 th week after sino-aortic baroreceptor deafferentation.

Also at the end of the 5 th week (see Methods) blood pressure (fig. 1a) and $\mathrm{dp} / \mathrm{dt}_{\mathrm{max}}$ (fig. $1 \mathrm{~b}$ ) in rats with neurogenic hypertension were significantly higher than in shamoperated rats. However, no significant changes in heart rate between both groups of rats could be observed (not depicted).

\section{Plasma catecholamines}

In rats with neurogenic hypertension circulating plasma noradrenaline concentrations were raised significantly to $357 \pm 44.4 \mathrm{pg} / \mathrm{ml}$ and circulating adrenaline concentrations to 278 $\pm 43.8 \mathrm{pg} / \mathrm{ml}$ when compared with sham-operated rats $(192 \pm 29 \mathrm{pg} / \mathrm{ml} \mathrm{NA} ; 107 \pm 26.4 \mathrm{pg} /$ $\mathrm{ml} \mathrm{A}$; fig. 2). There was no difference in circulating dopamine concentrations between both groups of rats.

\section{Heart catecholamines}

The heart weight of neurogenic hypertensive rats $(1107 \pm 39 \mathrm{mg})$ was significantly higher $(p<0.01)$ than that of sham-operated rats $(911 \pm 38 \mathrm{mg}$ ). In addition, there was also a significant difference $(\mathrm{p}<0.05)$ between the heart-body ratio of neurogenic hypertensive rats $\left(302 \times 10^{-5}\right)$ and control rats $\left(273 \times 10^{-5}\right)$. The noradrenaline content of the hearts in neurogenic hypertensive rats was significantly decreased when compared with sham-operated control animals (fig. $3 \mathrm{a}$ ). The adrenaline and dopamine contents of hearts between the both groups of rats showed no difference. In order to obtain some information about the changes in heart weight and observed differences in noradrenaline content of the heart we have calculated the total noradrenaline concentration of the heart, i.e., noradrenaline content per heart. The hearts of neurogenic hypertensive rats have a total noradrenaline amount of $881 \pm 54.2 \mathrm{ng}$ and the hearts of controls $853 \pm 23.5 \mathrm{ng}$. The difference was not significant. 


$$
\begin{aligned}
& \text { BLOOD PRESSURE } \\
& \left(\mathrm{mmHg} \times 10^{-1}\right)
\end{aligned}
$$$$
\begin{aligned}
& D P / D T_{\max } \\
& \left(\mathrm{mmHg} / \sec \times 10^{-3}\right)
\end{aligned}
$$

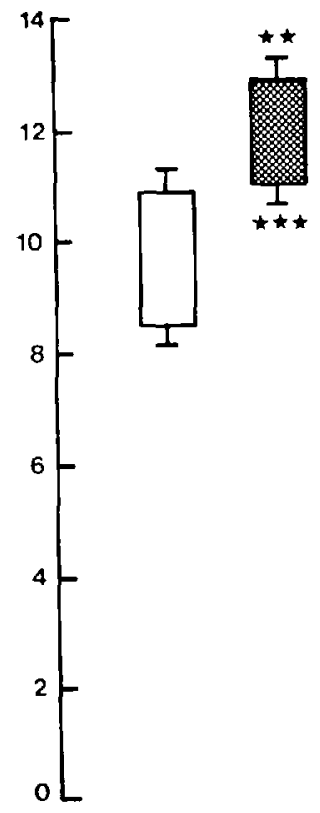

a

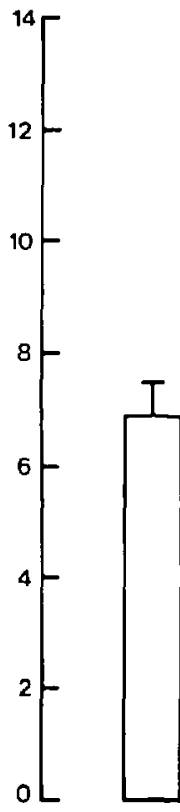

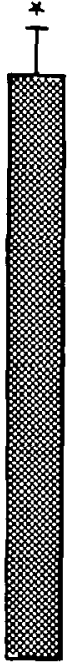

b

Fig. 1. Blood pressure $(1 \mathrm{a})$ and maximum rate of left ventricular pressure rise $\left(d p / d t_{\max }, 1 \mathrm{~b}\right)$ in shamoperated normotensive (white columns, $n=7$ ) and neurogenic-hypertensive rats (hatched columns, $n=$ 6) 5 weeks after total sino-aortic baroreceptor deafferentation. Significance levels: ${ }^{*}=p<0.05,{ }^{* *}=p$ $<0.01,{ }^{* * *}=\mathrm{p}<0.001$.

\section{Adrenal medulla}

In adrenal glands of rats with sino-aortic deafferentation adrenaline content was significantly increased ( $\mathrm{p}<0.01$; fig. $3 \mathrm{~b}$ ). However, no changes in dopamine and noradrenaline contents between both groups of rats could be observed. The wet weight of adrenal glands (55.2 $\pm 3.7 \mathrm{mg}$, hypertensive animals and $61.9 \pm 4.3 \mathrm{mg}$, sham-operated animals) was similar.

\section{Correlations}

In rats with neurogenic hypertension we observed a positive linear correlation between circulating plasma noradrenaline concentrations and $\mathrm{dp} / \mathrm{dt}_{\max }$ (fig. 4). However, in shamoperated rats we did not find a significant correlation $(r=0.214)$ between these parameters. Circulating noradrenaline and $\mathrm{dp} / \mathrm{dt}_{\max }$ were obtained at the same time from the last day of the 5 th week, as is mentioned above. 
PLASMA CATECHOLAMINES

$\left.(p g / m) \times 10^{-2}\right)$

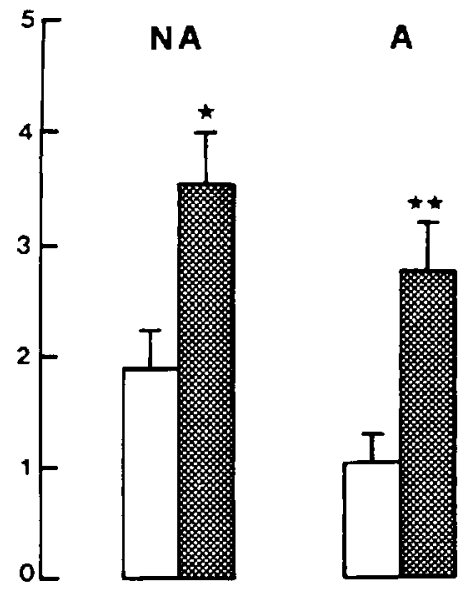

Fig, 2. Circulating plasma catecholamine concentrations (noradrenaline $=\mathrm{NA}$ and adrenaline $=\mathrm{A}$ ) in sham-operated controls (white columns, $n=7$ ) and neurogenic-hypertensive rats (hatched columns, $n$ =6) 5 weeks after total sino-aortic baroreceptor deafferentation. Significance levels see fig. 1 .

\section{Discussion}

Investigations by Kvetnansky et al. (21) have demonstrated that handling and repeated immobilization of rats resulted in enhanced circulating plasma catecholamine concentrations as well as increased activity of plasma dopamine- $\beta$-hydroxylase. Therefore it is important to measure haemodynamic parameters and collect blood samples in rats without handling in a quiet room. In our study we have performed all experiments according to the conditions mentioned above.

Our results confirm that chronic neurogenic hypertension persists in rats also 5 weeks after total sino-aortic deafferentation (SAD, Krieger, 1964). Earlier reports described elevated blood pressure in this model of hypertension up to 4 weeks after deafferentation (3, 5). We could demonstrate a significant elevation of blood pressure and an increase in $\mathrm{dp} /$ $\mathrm{dt}_{\max } 5$ weeks after baroreceptor deafferentation. Also an increase in heart-body ratio as an index for heart hypertrophy was observed, as has been reported for genetic hypertensive rats (4). We also obtained a positive correlation between plasma noradrenaline concentration and $\mathrm{dp} / \mathrm{dt}_{\max }$.

On the other hand noradrenaline content in hearts of SAD rats was significantly diminished when calculated per $g$ wet weight. The decreased noradrenaline content of 
HEART CATECHOLAMINES

$$
\text { (ng/g W.W. } \times 10^{-2} \text { ) }
$$

DA

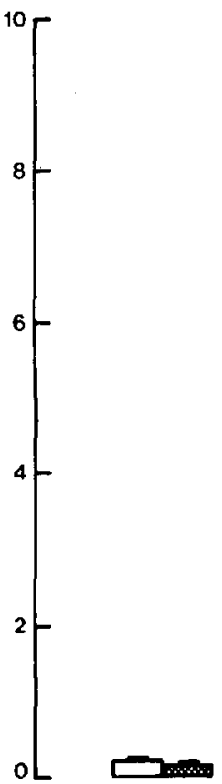

NA

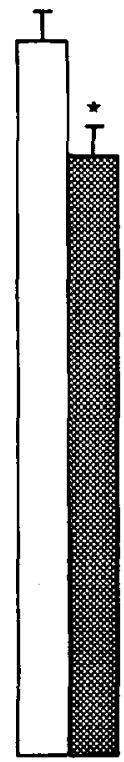

a
ADRENAL MEDULLA CATECHDLAMINES<smiles></smiles>

A

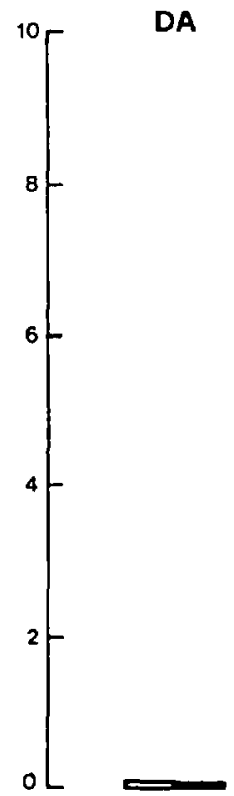

A

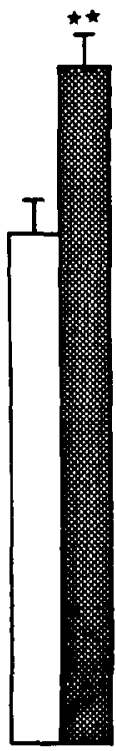

b

Fig. 3. Heart catecholamines ( $3 \mathrm{a})$ and adrenal medullary catecholamines (dopamine $=$ DA, noradrenaline $=\mathrm{NA}$ and adrenaline $=\mathrm{A}, 3 \mathrm{~b}$ ) in sham-operated controls (white columns, $\mathrm{n}=8$ ) and neurogenic-hypertensive rats (hatched columns, $\mathrm{n}=6$ ) 5 weeks after total sino-aortic baroreceptor deafferentation. Significance levels see fig. 1.

neurogenic hypertensive rat hearts is due to the muscular hypertrophy of these hearts because the total amount of heart noradrenaline content in both groups was similar. It is possible that significantly increased circulating plasma noradrenaline of SAD rats is nevertheless the result of an enhanced release by the heart or other sympathetic structures, probably elicited by stimulation of presynaptic $\beta_{2}$-adrenoceptors through high circulating adrenaline concentrations $(22,23)$. This would imply an enhanced cardiac noradrenaline turnover.

Elevated circulating plasma noradrenaline and adrenaline concentrations, (fig. 2), as well as the increased adrenaline content in the adrenal medulla, (fig. $3 \mathrm{~b}$ ) indicate that enhanced peripheral sympatho-adrenal activity, probably in addition to increased heart work, contribute to elevated blood pressure. The results are in agreement with observations of Alexander et al. (2) and Chalmers et al. (5), who reported elevated dopamine- $\beta$-hydroxylase activity in plasma and increased sympathetic activity in the spinal cord of chronic hypertensive rats as well as alterations in catecholamine levels and in phenylethanolamine-n-methyltransferase activity in a few brain nuclei and the pineal gland, time dependent since sinoaortic deafferentation was performed (27).

In contrast to our results, Alexander et al. (3) reported no changes in circulating noradrenaline and adrenaline in rats three and six weeks after baroreceptor deafferentation 


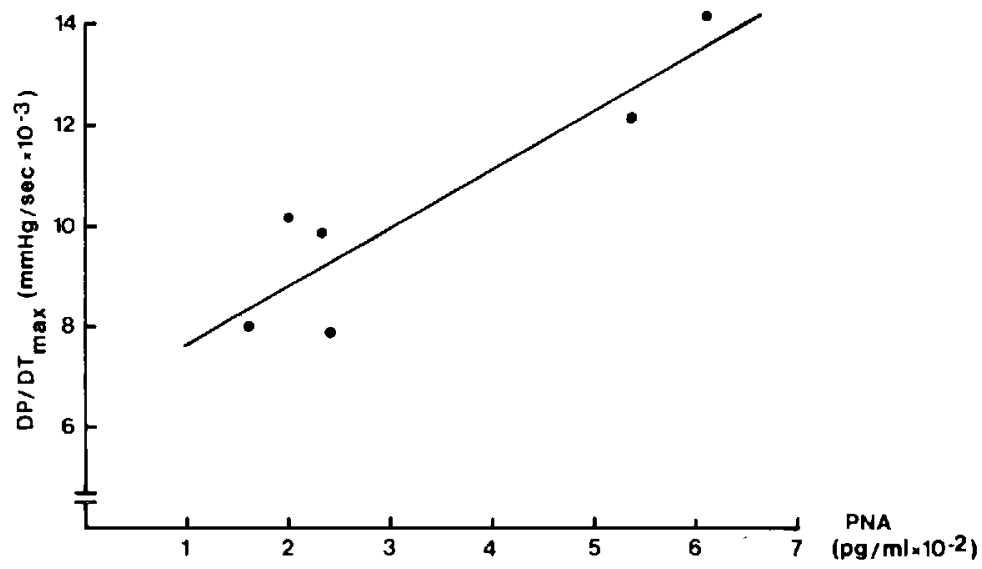

Fig. 4. Correlation between circulating plasma noradrenaline (PNA) and maximum rate of left ventricular pressure rise $\left(\mathrm{dp} / \mathrm{dt}_{\max }\right)$ in neurogenic-hypertensive rats. $\mathrm{r}=0.91, \mathrm{p}<0.05$.

when compared to controls. However, their basal values for noradrenaline and adrenaline in control animals are much too high (approximately $400 \mathrm{pg} / \mathrm{ml}$ ). This may be due to inadaequate sampling of blood specimen (noise, handling etc.).

Enhanced formation of catecholamines by the adrenal medulla during the development of hypertension in genetic and experimental (DOCA-salt) hypertensive rats has been reported recently $(16,17)$. In addition, it has been shown that blood pressure was significantly reduced after depletion of the catecholamines in the adrenal medulla of rats after administration of a hexahydropyrazinoindol compound (10).

In this context it is of interest that chronic administration of adrenaline produces elevated blood pressure in rats (22). An increased level of circulating adrenaline has also been observed in patients with essential hypertension and especially in young patients with essential hypertension $(11,13)$.

From our results we conclude that deafferentation of baroreceptors resulted in enhanced sympatho-adrenal activity/reactivity, leading to increased cardiac work and possibly vasoconstriction by stimulation of $\alpha_{1}$-adrenoceptors, thereby elevating blood pressure. An impaired function of baroreceptors may also significantly contribute to other forms of experimental hypertension e.g. Dahl S rats (14) as well as to essential hypertension at the early stage in humans (1).

\section{References}

1. Abboud FM (1982) The sympathetic nervous system in hypertension: State-of-the art review. Hypertension 4 (suppl II) II 208-II 2

2. Alexander N, McClaskey J, Maronde RF (1976) Elevated plasma dopamine beta hydroxylase activity in rats with neurogenic hypertension. Life Sci 18:655-662

3. Alexander N, Velasquez MT, Decuir M, Maronde RF (1980) Indices of sympathetic activity in the sinoaortic-denervated hypertensive rat. Am J Physiol 238:H521-H526

4. Bürger SB, Strauer BE (1981) Left ventricular hypertrophy in chronic pressure load due to spontaneous essential hypertension. I. Left ventricular function, left ventricular geometry, and wall 
stress. In: Strauer BE (ed) The heart in hypertension. Springer Verlag, Berlin Heidelberg New York, pp 13-35

5. Chalmers JP, Petty MA, Reid JL (1979) Participation of adrenergic and noradrenergic neurones in central connections of arterial baroreceptor reflexes in the rat. Circ Res 45:516-522

6. Cowley AW, Liard JF, Guyton AC (1973) Role of the baroreceptor reflex in daily control of arterial blood pressure and other variables in dogs. Circ Res 32:564-576

7. DaPrada M, Zürcher G (1976) Simultaneous radioenzymatic determination of plasma and tissue adrenaline, noradrenaline and dopamine within the femtomole range. Life Sci 19:1161-1174

8. De Champlain J, Krakoff LR, Axelrod J (1967) Catecholamine metabolism in experimental hypertension in the rat. Circ Res 20:136-145

9. DeQuattro V, Nagatsu T, Maronde R, Alexander N (1969) Catecholamine synthesis in rabbits with neurogenic hypertension. Circ Res 24:545-555

10. Dominiak P (1977) Angriffspunkte von Antihypertensiva am sympathoadrenalen System der Ratte: Pharmakologische, biochemische und histochemische Untersuchungen. Inaugural Dissertation, Frankfurt/Main

11. Dominiak P, Grobecker H (1982) Elevated plasma catecholamines in young hypertensive and hyperkinetic patients: Effect of pindolol. Br J Clin Pharmacol 13:381S-390S

12. Fink GD, Kennedy F, Bryan WJ, Werber A (1980) Pathogenesis of hypertension in rats with chronic aortic baroreceptor deafferentation. Hypertension 2:319-325

13. Franco-Morselli R, de Mendonca M, Bandouin-Legros M, Guichency P, Heyer P (1979) Plasma catecholamines in essential human hypertension and in DOCA-salt hypertension of the rat. In: Meyer P, Schmitt $\mathbf{H}$ (eds) Nervous system and hypertension. Flammarion, Paris, pp 287-296

14. Gordon FJ, Mark AL (1983) Impaired baroreflex control of vascular resistance in prehypertensive Dahl S rats, Am J Physiol 245:H210-H217

15. Grobecker H, Roizen MF, Weise V, Saavedra JM, Kopin IJ (1975) Sympathoadrenal medullary activity in young, spontaneously hypertensive rats. Nature 258:267-268

16. Grobecker H, Saavedra JM, McCarty R, Chinch CC, Kopin IJ (1977) Dopamin- $\beta$-hydroxylase activity and catecholamine concentration in plasma: Experimental and essential hypertension. Postgrad Med J 53:43-48

17. Grobecker H, Saavedra JM, Weise V (1982) Biosynthetic enzyme activities and catecholamines in adrenal glands of genetic and experimental hypertensive rats. Circ Res 50:742-746

18. Kissinger PT, Brüntlett CS, Shoup RE (1981) Neurochemical applications of liquid chromatography with electrochemical detection. Life Sci 28:455-465

19. Kopin IJ (1979) Plasma catecholamines in human and experimental hypertension. In: Meyer P, Schmitt $H$ (eds) Nervous system and hypertension. Wiley Flammarion, Paris, pp 267-276

20. Krieger EM (1964) Neurogenic hypertension in the rat. Circ Res 15:511-521

21. Kvetñanský R, Sun CL, Lake CR, Thoa N, Torda T, Kopin IJ (1978) Effect of handling and forced immobilization on rat plasma levels of epinephrine, Endocrinology 103:1868-1874

22. Majewski H, Tung L-H, Rand MJ (1981) Adrenaline-induced hypertension in rats. J Cardiovasc Pharmacol 3:179-185

23. Majewski H, Tung L-H, Rand MJ (1982) Adrenaline activation of prejunctional $\beta$-adrenoceptors and hypertension. J Cardiovasc Pharmacol 4:99-106

24. Okamoto K (1972) Spontaneous hypertension. Its pathogenesis and complications. Igaku Shoin Ltd, Tokyo

25. Peuler JD, Johnson GA (1977) Simultaneous single isotope radioenzymatic assay of plasma norepinephrine, epinephrine and dopamine. Life Sci 21:625-636

26. Planz G, Wiethold G, Appel E, Böhmer D, Palm D, Grobecker H (1975) Determination of acute changes of sympathetic activity in man: correlation between enhanced dopamine- $\beta$-hydroxylase activites and catecholamine concentrations in plasma. Eur J Clin Pharmacol 8:181-188

27. Saavedra J, Alexander N (1983) Catecholamines and phenylethanolamine $N$-methyltransferase in selected brain nuclei and in the pineal gland of neurogenically hypertensive rats. Brain Res 274:388-392

28. Saavedra JM, Fernandez-Pardal J, Guicheney P, Furness JB, McCarty R, Rouot B, Correa FM (1981) Heart catecholamines in genetic hypertension. In: Delius W, Gerlach E, Grobecker H, 
Kübler W (eds) Catecholamines and the heart. Recent advances in experimental and clinical research. Springer Verlag, Berlin Heidelberg New York

29. Saavedra JM, Grobecker H, Axelrod J (1976) Adrenaline-forming enzyme in brain stem: Elevation in genetic and experimental hypertension. Science 191:483-484

30. Saavedra JM, Grobecker H, Axelrod J (1978) Changes in central catecholaminergic neurons in the spontaneously (genetic) hypertensive rat. Circ Res 42:529-534

31. Sachs L (1978) Angewandte Statistik. Springer Verlag, Berlin Heidelberg New York

Received April 4, 1985

Authors' address:

Prof. Dr. med. P. Dominiak, Physiologisches Institut, Universität München, Pettenkoferstraße 12, 8000 München 2, F.R.G. 